\title{
Collaborative Inquiry with Men Who Use Intimate Partner Violence: Service User Perspectives on Expertise in Domestic Violence Services for Men
}

\author{
Rebecca Jury $^{1}$ (D) \\ Accepted: 20 January 2022 / Published online: 27 January 2022 \\ (c) The Author(s) 2022
}

\begin{abstract}
Concerns have been expressed regarding the efficacy of services for heterosexual men who use intimate partner violence. In addition, there has been limited research into the perspectives of these men regarding their use of services. The Australian study outlined in this article sought to examine the experiences of heterosexual men who use intimate partner violence (IPV) when they access domestic violence services. Collaborative inquiry was undertaken with men who were attending a residential domestic violence service to explore the research question; What does expertise look like in domestic violence services for men? When discussing expertise, twenty men identified four themes: lived experience and book knowledge, services and supports, professional helping skills and expertise, and non-professional helping and expertise. These collaborative researchers described expertise as a product of book knowledge and lived experience knowledge, indicating these knowledges could be located within the one person or shared between professionals and service attendees. The informants suggested cultural mentoring, peer support and co-production are important inclusions in men's domestic violence services. They also highlighted positive peer affirmations as supporting their behaviour change and suggested sociological frameworks are central to successful interventions with men. Men who use IPV may have important insights about expertise in domestic violence services for men which can inform future practice.
\end{abstract}

Keywords Domestic violence $\cdot$ Men who use violence $\cdot$ Perpetrators $\cdot$ Therapeutic communities $\cdot$ Collaborative inquiry

\section{Introduction}

Men who use intimate partner violence (IPV) in heterosexual relationships may be unwilling service participants and may have multiple issues, such as drug and alcohol addiction and mental health issues, alongside their use of violence and controlling behaviours. Men who use IPV can be likely to relapse to use of violence after receiving services (Centre for Innovative Justice, 2016). Despite increased funding and a renewed focus on policy development in the Australian domestic violence service sector, there appears to have been no substantial decrease in intimate partner violence in the last five to ten years (Australian Bureau of Statistics, 2018).

Rebecca Jury

r.jury@ecu.edu.au

1 School of Arts and Humanities, Social Work Program, Edith Cowan University, PO Box 1712, Bunbury, Western Australia, Australia
This mirrors domestic violence policy and practice outcomes internationally (World Health Organization, 2013).

\section{Treatment Approaches}

This article focuses on men who use violence and who are in heterosexual relationships. In Australia, approaches to addressing men's violence in heterosexual relationships has included men's behaviour change programs, judicial responses to intimate partner violence, integrated service responses and focused safety measures for women and children (Diemer et al., 2015). The development of these approaches has mirrored the historical development of service responses to men's intimate partner violence in the USA (Barner \& Carney, 2011; Day et al., 2009). The apparent lack of impact of targeted interventions on men's use of IPV, has led to the content of men's behaviour change programs being questioned (Day et al., 2009; Gondolf, 2011). Approaches such as Cognitive Behavioural Therapy 
and psychoeducational programs have shown some positive effect on the behaviour of men who use IPV (Hasisi et al., 2016). However, it is suggested failure to challenge gender norms in such programs through sociological approaches undermines long-term behaviour change (for example, Flood, 2015). Gondolf (2011) critiques one-size-fits-all approaches to men's violence and suggests a greater program focus on cultural factors and cognitive behavioural approaches could prove effective for reducing men's violence. He further suggests approaches to accountability in judicial responses to heterosexual men's violence are inadequate, with women's safety being jeopardised. Evaluation of interventions aimed at addressing men's violence has relied on quantitative approaches but, with low consistency between domestic violence programs, the validity of these evaluations is questionable (Akoensi et al., 2013; Gondolf, 2011; Portnoy \& Murphy, 2017; State of Victoria, 2016).

It has been suggested men who use IPV in heterosexual relationships are silent about causes of IPV, their responsibilities in desisting from violence and their use of human services to address their use of violence (Roguski \& Gregory, 2014; Westmarland \& Kelly, 2012). Men who use IPV also seem absent from service evaluation and feedback processes and from participation in research, despite evidence that service users who may be resistant/avoidant, hard to reach or involuntary participants can identify the professional skills and program components that assist them (Buckley et al., 2011; Keenan, 2012, p.283; Portnoy \& Murphy, 2017). Men who use IPV may have valuable input regarding the planning, provision and evaluation of domestic violence services for men. New information about how men access services and the barriers and facilitators they experience could add to the existing literature and provide new considerations for service approaches, and education of human services professionals and students.

The research described in this article sought to expand current understandings of the opportunities and challenges men in heterosexual relationships may face when accessing domestic violence services. This research may contribute to better understanding of these men's experiences, identify gaps in services and identify aspects of services that impact men's behaviour change. This study is part of a larger participatory action research project which examines the lived experience of heterosexual men who use IPV and the incorporation of their lived experiences into learning resources for social work education (Jury \& Boxall, 2018, 2021).

\section{Methodology and Methods}

The research described in this article was granted full institutional ethics approval (Project number 13139) and was undertaken in Australia at a residential domestic violence service for heterosexual men who use IPV. At the time of the research, the service utilised a multi-level approach to men's use of violence. This approach included a Duluth-based integrated service approach aimed at enhancing women and children's safety and men's accountability (Diemer et al., 2015) and a therapeutic communities model as popularised in residential drug and alcohol treatment (De Leon \& Unterrainer, 2020). The service also maintained a sociological perspective focusing on the need to challenge and change social norms regarding gender in order to reduce intimate partner violence (Jewkes et al., 2015). These broader frameworks were supported by group and individual therapy based on invitational narrative approaches (Jenkins, 1990) and psychoeducational approaches.

\section{Co-Researchers}

A total of 20 men, aged 25 to 55 years, participated in the research over a 16-week period. Co-researchers were from a range of cultural backgrounds and identified as First Nations peoples from Australia (Aboriginal) and New Zealand (Maori), White Caucasian, Pakistani, Indian, Arabic and South Sea Islander peoples. Despite differences in cultural backgrounds, the men were all from working class and/ or low socio-economic background and identified as being heterosexual. Men accessed the domestic violence service through different mechanisms; voluntarily or through legal mandate/s. However, it is acknowledged men who use IPV are more likely to be legally and/or socially mandated by friends and family to attend services, due to the ramifications of the types of violent behaviours they have used towards family members (Jury \& Boxall, 2018). The residents were therefore not presumed by the researcher to be voluntary service attendees, even if not legally mandated to attend men's services.

All participants had experience of working with human service workers in a range of settings and many had life challenges such as legal sanctions and criminal charges, pending court matters, family court or child welfare services involvement, and mental health, housing, and drug and/or alcohol issues. None of the men had a psychiatric diagnosis, and none were currently employed as the service requires full time engagement in the therapeutic program. Ninety percent (18 men) had adverse childhood experiences or ACE (Felitti et al., 1998) including witnessing domestic violence and experiencing physical and/or sexual violence. Eighty percent of the participant group (16 men) had either completed high school education or a trade school certificate. All participants were parents with most either having no current contact or supervised contact with their children. The relationship status of the men was difficult to determine as, 
according to the men, these statuses were changeable over the period of the research.

\section{Method}

Collaborative Inquiry (CI) is a qualitative methodology which is initiated by one or more initiating researchers who share an issue of concern (Bray et al., 2000). The initiating researcher invites co-researchers (research participants) from within the community of interest to explore a research question. In CI, peer collaboration is employed, where the focus is on breaking down power relationships by sharing expertise evenly between the initiating researcher(s) and the coresearchers, creating the potential for authenticity and reciprocity in the process (Bridges \& McGee, 2011). In action, this methodology facilitates relationship formation between co-researchers around an issue of concern (Sugiman, 2006) and provides the opportunity to "move away from passive participation [in research] to active involvement" (Gibbs, 2001, p 698).

Engagement and relationship building was integral to research with participants who had low or no previous research or service evaluation experience. The CI method offered opportunities to foster collaborative discussion and engagement which mirrored the therapeutic approach of the men's residential domestic violence service. Collaborative Inquiry and invitational narrative approaches to men's violence share a common epistemological framework, social constructionism, which centres on collaboration and narrative in action-based research (Gergen \& Gergen, 2008). The initiating researcher held a strong feminist lens, identifying that liberation and equality for women requires broad accountability from men for co-creating a new reality that includes the full and equal participation of all genders in social and political life (New, 2003). This equality presumes limited power relationships between all parties (New, 2003; Sayer, 2000). The initiating researcher held awareness of places where power was situated. This included the relationships between participants and their partners, participants and the researcher, and participants and human services organisations (Letherby, 2011).

Bray et al. (2000) describe CI methodology as beginning with a broad research question that co-researchers can explore from many perspectives, making their own meaning from the discussion that arises. The initial research question in this project was what does expertise look like in domestic violence services for men? As the collaboration progressed, the co-researchers and initiating researcher worked together to develop further research questions as new ideas arose.

In line with the CI approach a series of seven two-hour conversations were held over a four-month period. The meetings were held at a meeting room at the residential service, with one initiating researcher and six to seven co-researchers utilising "a process consisting of repeated episodes of reflection and action" (Bray et al., 2000, p 6) to explore the research question and generate new understanding of the issue/s of concern (Stewart, 2005). Service-based communities are often temporary and are focussed around a common experience of sharing service experiences and supports, rather than intrinsic qualities which connect members to an on-going community of interest (Haigh \& Campling, 1999). The residential domestic violence service provided a unique opportunity to explore the experiences of service users who were embedded in a service environment for a three to sixmonth period.

Men who were current residents at the residential domestic violence service, were invited to participate in research meetings which were audio-recorded. Each meeting followed a pattern, with the co-researchers and initiating researcher discussing and analysing outcomes from the last group meeting, developing a plan for the current session and then concluding the meeting by identifying the core ideas generated in the discussion. These key ideas were collated by the initiating researcher, and it was these ideas and the audio transcript of the session that were brought back to each group meeting for confirmation, discussion and analysis by the co-researchers. The men generated verbal discussion in the meetings but also provided drawings and notes to be included in the research materials (research artefacts).

The initiating researcher had planned for one group of co-researchers to continue meeting until the group identified that exploration of the research question had reached a natural end. However, the co-researchers had many demands in their lives and were often transient, so consistency of attendance was difficult. Unlike traditional CI, this group became an evolving collaboration with men attending once or twice, multiple consecutive times, or sporadically. Although the changing group membership did not conform to the traditional process for CI, the co-researchers reasoned this temporary or changeable collaborative community mirrored their daily lives. New participants were not recruited by the initiating researcher, but by the existing co-researchers, perhaps signifying group cohesiveness and ownership of the research. The co-researchers approached each new resident of the service and invited them to the research group meetings, with any new attendees being provided with consent documents by the initiating researcher at the start of each group meeting.

One outcome from this changeable and transient collaborative group was the men took on the role of maintaining and relaying the outcomes of the group meetings to other coresearchers, thereby keeping new or returning co-researchers up to date with discussions. There appeared to be no distinct differences between co-researchers who attended sporadically or more continually, as the reasons for sporadic 
attendance appeared to be daily life demands for these men, such as court appearances, prison internment and/or external service attendance. Within three weeks of the conclusion of the research, all co-researchers had left the service with some leaving the program early and others graduating from the program. While none of the co-researchers were involved directly in the writing of this article, the findings/discussion chapter includes the themes, ideas and interpretations which were developed and approved by the men through the analysis process.

\section{Data Analysis}

Audio-recordings of each group meeting were transcribed and stored in NVivo software by the initiating researcher. The notes and pictures (research artefacts) provided by the co-researchers were also stored. The initiating researcher brought these transcripts and research artefacts to each group meeting. Co-researchers and the initiating researcher used Wolcott's (1994) description, analysis and interpretation approach to interrogate the information sources to develop themes arising from the CI group meetings.

The research artefacts and transcripts were systematically coded and categorised (using highlighters) with themes being identified, utilising an exhaustive process whereby coding continued until no new themes were generated. The co-researchers also shifted some ideas between the named themes, finding what they saw to be the best fit. This approach provided for a cyclical analysis of the data as the themes were returned to with each meeting, providing new co-researchers opportunities to add ideas and interrogate existing themes. By analysing at each group meeting, all co-researchers had opportunities to engage in analysis, even if sporadic in attendance.

The questions which guided the analysis were

1. What was said about expertise in the collaborative group?

2. What were the co-researchers' experiences of using services for domestic violence?

3. Were there things that helped and things that did not help when co-researchers accessed services?

Question 1 linked to the research question originally brought to the CI group by the initiating researcher. Questions 2 and 3 were developed by the initiating researcher and co-researchers in the first group meeting of the CI. These questions were asked by the initiating researcher and the co-researchers of each group transcript and the research artefacts. The themes identified through this circular process of analysis are outlined in the section to follow.

\section{Findings and Discussion}

The initiating researcher and co-researchers identified four themes during the CI. The co-researchers confirmed these key themes at their final group meeting and requested these form the basis of the journal article that would be written about their research. The initiating researcher has combined findings and discussion in this article to improve the readability and narrative of the paper (O'Sullivan \& Jefferson, 2020). This decision centred on making the paper readable for lay-persons, such as the co-researchers.

\section{Theme 1 Book Knowledge and Lived Experience Knowledge:The Expertise of Shared Knowledge/S}

Co-researchers defined two types of expertise; book knowledge and lived experience knowledge. Book knowledge was described as the product of reading academic books and undertaking university study. Lived experience knowledge was described as knowledge gained through having the direct lived or living experience of an issue. Group members used these descriptors for a range of issues in their life such as, parenting, using violence against others, experiencing violence/abuse, drug and/or alcohol usage, mental health issues, imprisonment, and relationship issues. Some group members said they had experienced limited success at dealing with their own issues and needed a person with good book knowledge who could provide ideas they had not yet encountered. The co-researchers agreed the best combination of lived experience knowledge and book knowledge was where these two existed in the one person, as this could lead to knowledge which could be shared in a meaningful way with other men who use IPV.

Co-researchers identified their relationships with their children as a leading reason for instigating change in coresearchers' lives, a finding supported in other research with men who use IPV (Perel \& Peled, 2008; Roguski \& Gregory, 2014).

"For me and my partner, it was always about winning [the argument]....It basically came down to the children being apprehended... and that made me think whether [the relationship is] good for the kids or not" (Co-researcher 1).

The issue of parenting was raised many times during the group meetings. Co-researchers indicated facilitators of parenting groups should have lived experience in a parenting role to offer effective support, as they had attended 
groups where the facilitator was not a parent which had been unhelpful.

"a lot of people [staff] have come from a university... going into a job somewhere and probably never been in an environment where they have a household with multiple kids or say a mix blended family with different fathers....So they're not understanding that it's a hard situation to be in.... a constant juggling act to try to keep everyone happy in your household" (Coresearcher 2)

The men identified the parenting role as being central to their recovery as $90 \%$ of co-researchers reported adverse childhood experiences (ACEs), poor parental role models and low understanding of positive parenting behaviours.

Co-researchers suggested limitations of having lived experience knowledge without book knowledge, as people working in professional roles who have only lived experience knowledge may attempt to apply their experience to everybody without recognition of the importance of difference

I mean, everybody's different. It might have worked for the counsellor...but it might not work for myself or it might work for one of the other blokes but just not everybody as a whole (Co-researcher 5)

In group meetings 1 and 2, the co-researchers discussed the possibility of collaborative working relationships in domestic violence services, so expertise could be the product of a working relationship between a person with lived experience and a person with book knowledge, providing the relationship was equitable and respectful. The co-researchers suggested the exchange of expertise through this sort of working relationship could provide the opportunity for a book expert to be informed by a lived experience expert and vice versa, resulting in mutually beneficial and reciprocal learning. This idea was pursued through subsequent group meetings as a possible solution to the sharing of knowledge between professionals (book expert) and residents/clients (lived experience expert) in domestic violence services. Coresearchers said they had experienced this to some extent in domestic violence services but felt their ideas and opinions were sometimes devalued as they were viewed as untrustworthy or lacking insight into their own issues:

I feel like the perpetrator, and they [the professionals] are the expert. Like they're doing everything right and I'm nothing (Co-researcher 1)

In research that examined mental health care planning, Bee et al. (2015) suggest service users living with multiple issues highly value relational aspects of care planning, such as participatory decision making and strength-based approaches. Professionals in Bee et al.'s (2015) study were seen to value linear decision making and meeting organisational requirements; The co-researchers in the present study appeared to be describing relational aspects of professional and service user relationships, where both are positively impacted by the shared product of the relationship, a process referred to as co-production by researchers such as Mayer and McKenzie (2017). Co-production signifies a relationship is equal, respectful and focused on service user-led practice. Fledderus et al. (2015) suggest co-production may increase trust and participation by service users but may result in decreased certainty for organisations, thereby decreasing the professional's willingness to engage in co-production. With an increase in risk adverse practice in the human services (Ferguson, 2007), it is possible co-production may be seen to be too risky, particularly with a service user group who has used extreme violence such as men who use IPV. There have been unsuccessful attempts to engage heterosexual men who use IPV in conversations about co-production ( $\mathrm{McCa}-$ rry et al., 2018). In relation to men who use violence in same-sex relationships, research has suggested co-production in developing desistance resources can lead to positive outcomes for participants including self-reflection about psychosocial development and behaviours in relationships (Morris et al., 2019).

\section{Theme 2 Services and Supports: Expertise that Helps us Change our Violent Behaviour}

In relation to accessing human services to address their use of intimate partner violence in relationships, the co-researchers indicated they had attended non-residential weekly group counselling and the residential service in which they were residing at the time of the research.

Residential services were viewed more positively than non-residential services by all co-researchers due to the availability of a 24-h response by on-site staff, opportunities to learn daily living skills, such as cooking and cleaning, and the ability to practice communication and conflict resolution skills in a safe environment.

I don't think you can get help while you're still at home, if you know what I mean. I don't think it's going to work because you've got such a long process to do ... and that pressure in itself is enough to make you regress. Being here in the residential program has helped me to just totally relax and...keep my head together (Co-researcher 3)

The co-researchers indicated the use of male and female co-facilitators in residential and non-residential domestic violence services was essential as this provides examples of how men and women can interact in respectful ways.

Co-researchers identified barriers they had faced when accessing domestic violence services for men. These barriers 
were discussed as impacting on their ability to engage with services. These included difficulties with obtaining access to services, challenges of embedding long term behaviour change and cultural barriers. Accessing help for the first time was seen by co-researchers to be particularly difficult and all co-researchers had negative experiences of attempting to locate appropriate services or obtain referrals. Co-researchers identified there was low available information about services and supports, particularly as many of them lived with low literacy and most available information was in written form. They also said there was low knowledge in other human services about options for men who use IPV, and limited availability and long waiting times for most services:

It is hard enough to ask for help but when you then need to wait for three months it can be even harder. Then more things happen in your life and you can end up being in more trouble (Co-researcher 10)

A positive first attempt when accessing services has been reported to be linked to more positive longer term outcomes for men who use IPV (Campbell, Neil, Jaffe, \& Kelly, 2010). In relation to long-term behaviour change the co-researchers identified they must navigate new ways of being non-violent, but also confront the realities of the external world and their communities which remain unchanged. One co-researcher used the example of alcohol use in Australian communities, indicating when he had reached sobriety following a residential drug and alcohol program, family members and friends continued to offer him alcohol, with name calling (such as "pussy") following refusal. Co-researchers said this was complex and difficult to manage, sometimes causing confusion and despair when their outside communities did not match their new learning:

You can do all the courses and pass all the programs and that but you won't really know if it is working until you get back out there in society (Co-researcher 8)

But we mingle with society every day. I go down the shops, I go on report, I am mingling with the community every day (Co-researcher 9)

But when you go out there for a couple of days, what happens? Do you think you do ok and everything is under control? (Co-researcher 8)

Sometimes... (Co-researcher 9)

It's great to know I will get a certificate at the end, but it doesn't mean I am going to be a better person when I get back on the street. You can do everything you can to listen and learn but when you get back out there you are going to have to work pretty hard not to be the same person all over again (Co-researcher 17).

Pearce and Pickard (2013) describe two essential components for a successful therapeutic community: sense of belonging and responsible agency. The co-researchers indicated they felt a sense of belonging to the residential service and an increased ownership over their past violent behaviours, but disconnection between their therapeutic experience and their external world experience may undermine longer term change. When re-entering their communities, co-researchers indicated they were exposed to ongoing gender norms, past stressors and expectations by family members and/or friends they would revert to previous behaviours; suggesting the residential environment provided a buffer to these unchanged social viewpoints and behaviours.

Aboriginal men identified there was a lack of cultural support and knowledge in mainstream domestic violence services for men, with services lacking connections with Aboriginal elders and employing low numbers or no Aboriginal staff. The men said this detracted from their ability to recover from use of violence as their cultural ways of addressing issues were not offered.

Even though we are Aboriginal fellas, we're from different groups, different tribes, different family groups which is a massive influence on who we are...but staff don't understand that (Co-researcher 14).

For Aboriginal men connection to culture, country and community and Aboriginal-led approaches are central to positive recovery from using IPV (Department of Health and Human Services, 2019).

\section{Theme 3 Professional Helping and Expertise}

The co-researchers identified interpersonal skills which they deemed necessary for professionals who work in domestic violence services for men. These skills were compassion, rapport building, maintaining confidentiality, positive working relationships, empathy and trust. The co-researchers indicated these interpersonal skills were the basics required for practice. To ensure excellence for domestic violence professionals, there were some additional requirements for professional-client relationships; consistency, commitment and the ability to translate professional jargon. Consistency was defined as longevity, authenticity, stability in professional-service user relationships (for instance, the ability to maintain a relationship with a counsellor during co-researcher imprisonment), and ongoing discussions about relationship productivity, information sharing and confidentiality. Co-researchers reported difficulty in terminating non-productive relationships in services due to perceptions by the service or the professional that co-researchers had ulterior motives for wanting to end the relationship, beyond wanting a positive service outcome and wanting the right to choose their therapist or co-worker. Buckley et al. (2011) suggest 
service users with multiple issues have good insight into their broad service needs and can provide coherent feedback about professionals and service issues.

Professionals were described by the co-researchers as needing to hold commitment, credibility and authenticity. Co-researchers recalled interactions with professionals in domestic violence services who demonstrated ethical behaviour and who were described as having a "calling" to be in their profession;

it was different here, you know what I mean, the people you are dealing with really care, they're not just here for the pay (Co-researcher 4)

Providing domestic violence service support was described by the co-researchers as being more than a job; requiring a deep commitment by the professional. While having a professional calling is a contested concept in the literature (Duffy \& Dik, 2013), the co-researchers were clear about their meaning for this concept. They suggested professionals were at the workplace because they wanted to be there and not because of other enticements, such as money. This example of caring beyond the specific requirements of the professional role was indicated by co-researchers to be a key factor in their behaviour change as it provided a collaborative approach to becoming non-violent.

Co-researchers discussed translation as a role for professionals. This skill was acquired due to the professional's book knowledge which meant the professional could make sense of human service jargon which was often incomprehensible to the co-researchers. Co-researchers discussed the importance of feeling they could ask any question of staff without judgement or condescension.

In group counselling we have this thing that there is no such thing as a stupid question. Outside of the group I feel like I can't ask those questions because I feel like I am supposed to already know those things (Co-researcher 11)

Professional relationships were valued by co-researchers who described them as providing a means to explore confusing or unanswered questions about services, ways to be non-violent and relationship or family problems. Portnoy and Murphy (2017) identified the importance of domestic violence group facilitators creating an emotionally safe place for men who use IPV to explore their social, cultural and emotional issues. Professional relationships were viewed by co-researchers as providing more than just informational or educational content relating to domestic violence and were viewed as personal supports, utilised to address a range of life issues beyond the use of violence. Alongside these positive experiences, participants also described incidents of judgement and isolation when accessing services.
When you seek the help it's like your name is written in a book and you are gonna be judged on that book, you know what I mean? You're not being told, "Well done. You're really making a difference to your life and the life of your family and the people around you". You are instead seen as less than anyone else (Co-researcher 1)

Domestic violence is not a word you want to be associated with and that's because you're ashamed of that word and it's even worse if you're categorised as a domestic violence person (Co-researcher 9)

These two quotations describe a binary experience for the co-researchers where they attempt to seek help but find the experience of seeking help to be de-grading and stigmatising due to being shamed. Campbell et al. (2010) examined the help seeking experiences of 12 men who use IPV and identified a key issue was embarrassment and shame which then impacted on the man's willingness to seek supports. This reluctance could be the result of traditional gender roles around help-seeking, as suggested by Campbell et al. (2010), or the social stigma attached to being a perpetrator of family violence. Jenkins (2005) suggests facing shame should be distinguished from being shamed when men are working towards non-violence, with the former providing ways for men who use IPV to work toward restorative actions.

Most of the co-researchers (18 out of 20 or $90 \%$ ) identified a history of being subjected to violence, usually in their childhood, followed by their increased use of violence against women and other men as they grew to adulthood. Men who use IPV are often violent towards other men as well as their female partners with this behaviour possibly being linked to strong gender based ideas about gaining authority through violent means (Jewkes et al., 2015).

Co-researchers discussed their increasing use of violence despite their early-life contention they would not follow the same pattern as the person or people who had utilised violence against them in childhood. The identification with labels of both being a victim and a perpetrator complicated the co-researchers' ability to seek support from services; they questioned how they could deal with experiences of victimisation when they were only identified as perpetrators of violence. Co-researchers said once labelled as a perpetrator, experiences of victimhood were often ignored or put aside by professionals. Co-researchers indicated this was never discussed in the client/worker relationship and one co-researcher indicated;

they think we are using it as an excuse but that's not it at all. I just want to be able to talk about it (Coresearcher 12)

It is widely acknowledged in the literature adverse childhood events (ACE), such as witnessing or directly 
experiencing physical, emotional and sexual violence, may be linked with perpetration of violence towards others in adulthood (Felitti et al., 1998; Moulding, 2018; Richards et al., 2017). This has been explained in a variety of ways such as the normalisation of violence in childhood leading to lowered thresholds for usage of violence (Fulu et al., 2017), lack of development of coping skills leading to poor stress management in adult relationships (Roberts et al., 2011), increased mental health and addiction outcomes (Machisa et al., 2016) and the gendered discourses that may form part of ACE and frame men's responses to ACE (Moulding, 2018). While the literature is divided about these explanations, there is agreement that domestic violence services for men require a focus on trauma-informed practice to improve service outcomes for men; such an approach would clearly need to provide opportunities to talk about childhood violence (Voith et al., 2020).

\section{Theme 4 Non-professional Helping and Expertise}

Peer support, self-awareness, maintaining humour and developing a sense of purpose were identified as positive change mechanisms for men, with domestic violence services providing opportunities to enact these.

One identified area of expertise was peer support through assisting other men to integrate into the residential program when they first arrived;

We've got the experience and we are trying to help everyone else make their way through here. You try and make it as easy as you can. I've even taken on the role of introducing people into here. It helps people, you know, roll into the program a lot easier (Coresearcher 6)

The co-researchers indicated this was known as Grandfathering at the service; where an existing resident assisted a new resident to integrate into the residential service. This role was seen to be essential and not one that could be undertaken by a professional staff member. Residential services that utilise a therapeutic communities model are recognised as having positive impact on a resident's sense of belonging and ownership of behaviours which in turn can impact on longer term behaviour change (Pearce \& Pickard, 2013).

Peer relationships may also be a factor in behaviour change with Doogan and Warren (2017) identifying residents of therapeutic communities respond more favourably towards peer affirmations than affirmations from professionals, and use this peer feedback to create new nonviolent identities. Co-researchers reported the sense of belonging and purpose they gained through positive peer interactions, such as Grandfathering, was a key component in their recovery process.

Co-researchers also indicated they value hearing the recovery stories of other men who use violence. Roguski and Gregory (2014) highlight men who use IPV want to hear stories of change from other men and request mentors, but there is lack of guidance as to what makes a person a good mentor or role model.

It would be great to have people who've been through it - the groups, the counselling, all that stuff. Then they could help pave the way for us when we get [into services]. But how do you know they can walk the talk? (Co-researcher 18)

Sprang et al. (2020) suggest mentorship and bystander training programs could provide some ways forward for building a network of mentors and role models for men who use IPV.

The co-researchers described self-awareness as an awakening that could assist them to begin a process of change. The men defined self-awareness as the growing realisation of the impact of their behaviours on others and themselves. They acknowledged this could happen before accessing services;

maybe you grow up, maybe you mature, maybe you get sick of your life, you know what I mean? What made me realise was asking myself one day why I was drinking all the time and the answer was because I was unhappy because I didn't know how to deal with what was happening all around me so I would just block it out by getting drunk all the time (Co-researcher 2)

But they could also experience their first self-awareness after they began accessing domestic violence services. The importance of raising the self-awareness of men who use IPV has been highlighted as this may lead to reduction of risk for use of violence towards female partners or expartners (Roguski \& Gregory, 2014; Westmarland \& Kelly, 2012). Co-researchers reported residential and non-residential domestic violence services had sometimes provided the first opportunity for self-reflection and awareness of connections between their thoughts, emotions and behaviours.

The co-researchers also discussed the expertise they held in domestic violence services. Co-researchers discussed how they could;

weed out the doers and the don'ters [in services] (Coresearcher 7)

These were the residents or group participants who were perceived as not being genuine in their help seeking.

it all comes down to experience, you know. It's easier for us to pick up that someone is on drugs, 
rather than staff. Coz they are hiding it from the staff but they don't tend to hide it from us as much (Coresearcher 6)

Maintaining a sense of humour despite challenging times was another place of expertise identified by co-researchers.

I was coming back here on the bus. The bus had been detoured from the usual route so me and [another resident] asked to be let off at a different stop which was close to [the service]. The bus driver got angry coz he knew about the service and what it was for. He said we shouldn't ask him to do anything for us. As we got off the bus the driver said, "It's all right for you, you dole bludger" ${ }^{1}$ ". I thought I could get angry but there's no point so I answered him by saying, "I'm not on the dole....I'm on sickness benefit!" We laughed and laughed but I was also proud that I had handled this situation ok and didn't get angry (Co-researcher 3).

The men discussed the need to maintain a grim sense of humour throughout help seeking due to the enormity of their past and present lives and the many obstacles they faced, such as learning to be non-violent, living with mental health and/or addiction issues, past experiences of violence (using violence and/or experiencing it from others), relationship issues and the loss of relationships with partners and children.

Many of the co-researchers were from cultural backgrounds that experience direct and indirect racism in Australia. The range of emotional, cultural and social issues the co-researchers live with could result in an experience of multiple stigmatised identities and societal rejection of their perspectives and personhood (Remedios \& Snyder, 2018). It is possible the comments by co-researchers are an attempt to create a culture of "undignified dignity" (Jensen, 2018, p. 20 ) in order to deflect stigma. Co-researchers said this grim humour was shared between residents and domestic violence professionals in the services they had accessed and, although unacknowledged to a great degree, it formed an important part of their experience.

In relation to informal support from family or friends, co-researchers said this was minimal. Co-researchers suggested their family and friends were often living with the same issues, could offer no advice or support and had limited knowledge of services for men who use IPV. Some coresearchers indicated they had been actively discouraged from seeking help by family members. Research indicates men who use IPV have often experienced poverty and

\footnotetext{
${ }^{1}$ A euphemism for someone who is unemployed and receives Government payments.

${ }^{2}$ Someone who is unemployed and unwell so can't search for employment and receives a Government payment
}

childhood abuse, and their families may not have the emotional resources to support them in their help seeking (Voith et al., 2020). Co-researchers indicated talking to friends was not an option for working out how to recover from using violence.

Some things you can't talk to your mates about (Coresearcher 1)

Yeah, coz they might think you are weak or something like that (Co-researcher 2)

Towns and Terry (2014) discuss the idea of "mateship" and how this impacts men's help seeking. The authors suggest the importance of sustaining relationships with male friends may outweigh the desire to seek help if the latter is viewed as non-masculine. Co-researchers in this present study identified a difference between the support from peers (other men in domestic violence services) and family or friends. Campbell et al. (2010), Flood (2015) and Roguski and Gregory (2014) highlight the difficulties of challenging gender norms with men who use IPV when their family members and communities are embedded with these same norms. Anderson et al. (2017) suggest domestic violence services have a dual responsibility to provide public-health approaches aimed at the whole community, as well as intensive group and individual programs to address IPV.

\section{Limitations}

The study was restricted to participants from one residential domestic violence service which utilised a therapeutic community model which may have impacted men's views about the importance of peer support and community engagement. To counter this, the researcher encouraged men to include reflections based on the men's experiences in all domestic violence services they had accessed: all co-researchers had accessed multiple services for men's use of violence. The method of choice was collaborative inquiry which requires longer term engagement for both initiating researchers and co-researchers and so may be challenging for domestic violence services or external researchers to replicate. Despite these limitations the research outlined in this article has identified themes that might have relevance for domestic violence services for men and ramifications for future research.

\section{Implications for Practice}

Firstly, men who use IPV reported that the domestic violence services they had accessed appeared to have limited knowledge or expertise about mentorship and engaging informal or cultural supports for men. With increased focus 
on Aboriginal men owning responsibility for violence in Aboriginal communities, mainstream domestic violence services may need to consider the limitations of White cultural competence measures (Herring et al., 2013) and engage local Aboriginal communities and organisations in co-planning supports for Aboriginal men. Bystander training and mentorships, such as cultural mentorships, could be offered to men who use IPV following their successful completion of a domestic violence program. As mentors, the men could build peer-to-peer relationships that could provide new approaches to addressing men's violence.

Secondly, co-researchers indicated there was low collaborative co-production between men who use IPV and professionals, and that adopting a co-production approach could improve service outcomes. Such approaches could include leveraging men's existing peer support skills, enhancing self-awareness and creating sense of purpose in men's services. Recovery frameworks for men who use IPV could include coping strategies such as the use of humour to fight stigma and how identify and build positive peer mentoring relationships.

Finally, co-researchers identified their informal support networks, such as friends and family, as a possible risk for their return to violent behaviours. It is indeed possible men who use IPV don't receive any positive affirmations from family, friends or general society for seeking help which can detract from their willingness to engage. In relation to residential communities, it may be important for services to enact greater integration with men's home environments during a residential stay to provide greater opportunities for men who use IPV to integrate their learning.

\section{Implications for Research}

Future research could explore the possible outcomes when co-production, cultural appropriate peer support and sociological interventions are introduced or increased within men's domestic violence services. Participants in such research could include men who use IPV and their families in separate collaborative inquiries. Further research could also explore CI as a longitudinal method with men who use IPV, to identify if there are long-term impacts.

\section{Conclusion}

The research findings suggest men who use IPV interventions can be engaged in discussions about their service use experiences. Including the perspectives of these men, may offer new ideas for the evaluation and re-shaping of domestic violence services.
Acknowledgements I acknowledge I live and work on Noongar Boodja and I pay my respects to Elders past, present and future. I acknowledge the Aboriginal and Torres Strait Islander peoples both past and present who were involved in the research described in this thesis. I thank them deeply for their knowledge and contribution to my ideas. I am committed to the recognition of First Nations Peoples as the ongoing custodians of the land on which I stand, Australia.

Funding Open Access funding enabled and organized by CAUL and its Member Institutions.

\section{Declarations}

Conflict of Interest The author reports no declarations of interest.

Open Access This article is licensed under a Creative Commons Attribution 4.0 International License, which permits use, sharing, adaptation, distribution and reproduction in any medium or format, as long as you give appropriate credit to the original author(s) and the source, provide a link to the Creative Commons licence, and indicate if changes were made. The images or other third party material in this article are included in the article's Creative Commons licence, unless indicated otherwise in a credit line to the material. If material is not included in the article's Creative Commons licence and your intended use is not permitted by statutory regulation or exceeds the permitted use, you will need to obtain permission directly from the copyright holder. To view a copy of this licence, visit http://creativecommons.org/licenses/by/4.0/.

\section{References}

Akoensi, T. D., Koehler, J. A., Lösel, F., \& Humphreys, D. K. (2013) Domestic Violence Perpetrator Programs in Europe, Part II:A Systematic Review of the State of Evidence. International Journal of Offender Therapy and Comparative Criminology, 57(10), 1206-1225. Retrieved from https://doi.org/10.1177/0306624X12 468110.

Anderson, J. F., Reinsmith-Jones, K., \& Reddington, F. P. (2017). Violence prevention in disadvantaged communities: The need for using criminal justice and public health approaches. Journal of Human Behavior in the Social Environment, 27(7), 743-744. Retrieved from https://doi.org/10.1080/10911359.2017.1353373.

Australian Bureau of Statistics. (2018). Victims of Family and Domestic Violence related offences. Retrieved from https://www.abs.gov. $\mathrm{au} /$ statistics/people/crime-and-justice/recorded-crime-victims/ latest-release

Barner, J. R., \& Carney, M. M. (2011). Interventions for intimate partner violence: A historical review. Journal of Family Violence, 26(3), 235-244. Retrieved from https://doi.org/10.1080/10926 770801921246

Bee, P., Price, O., Baker, J., \& Lovell, K. (2015). Systematic synthesis of barriers and facilitators to service user-led care planning. The British Journal of Psychiatry, 207(2), 104-114. Retrieved from https://doi.org/10.1192/bjp.bp.114.152447.

Bray, J. N., Lee, J., Smith, L. L., \& Yorks, L. (2000). Collaborative inquiry in practice : Action, reflection, and making meaning. Sage Publications.

Bridges, D., \& McGee, S. (2011). Collaborative inquiry: Reciprocity and authenticity. In J. Higgs (Ed.), Creative spaces for qualitative researching : Living research (pp. 211-222). Sense.

Buckley, H., Carr, N., \& Whelan, S. (2011). 'Like walking on eggshells': Service user views and expectations of the child protection 
system. Child \& Family Social Work, 16(1), 101-110. Retrieved from https://doi.org/10.1111/j.1365-2206.2010.00718.x.

Campbell, M., Neil, J. A., Jaffe, P. G., \& Kelly, T. (2010). Engaging abusive men in seeking community intervention: A critical research \& practice priority. Journal of Family Violence, 25(4), 413-422. Retrieved from https://doi.org/10.1007/ s10896-010-9302-z.

Centre for Innovative Justice. (2016). Pathways Towards Accountability: Mapping the Journeys of Perpetrators of Family ViolencePhase 1: Retrieved from https://ntv.org.au/wp-content/uploads/ 2020/06/Pathways-towards-accountability_CIJ.pdf

Day, A., Chung, D., O'Leary, P., \& Carson, E. (2009). Programs for men who perpetrate domestic violence: An examination of the issues underlying the effectiveness of intervention programs. Journal of Family Violence, 24(3), 203-212. Retrieved from https:// doi.org/10.1007/s10896-008-9221-4.

De Leon, G., \& Unterrainer, H. F. (2020). The therapeutic community: A unique social psychological approach to the treatment of addictions and related disorders. Frontiers in Psychiatry, 11(786). Retrieved from https://doi.org/10.3389/fpsyt.2020.00786.

Department of Health and Human Services. (2019). The Nargneit Birrang Framework: "To see the river" (Woiwurrung). .Melbourne, Australia: V. Government. Retrieved from https://conte nt.vic.gov.au/sites/default/files/2020-01/Nargneit\%20Birrang\% 20Framework\%20Report\%20December\%202019_0.pdf

Diemer, K., Humphreys, C., Laming, C., \& Smith, J. (2015). Researching collaborative processes in domestic violence perpetrator programs: Benchmarking for situation improvement. Journal of Social Work, 15(1), 65-86. Retrieved from https:// doi.org/10.1177/1468017313504682.

Doogan, N. J., \& Warren, K. (2017). A network of helping: Generalized reciprocity and cooperative behavior in response to peer and staff affirmations and corrections among therapeutic community residents. Addiction research \& theory, 25(3), 243-250. Retrieved from https://doi.org/10.1080/16066359.2016.12498 64.

Duffy, R. D., \& Dik, B. J. (2013). Research on calling: What have we learned and where are we going? Journal of Vocational Behavior, 83(3), 428-436. Retrieved from https://doi.org/10.1016/j.jvb. 2013.06.006

Felitti, V. J., Anda, R. F., Nordenberg, D., Williamson, D. F., Spitz, A. M., Edwards, V., \& Marks, J. S. (1998). Relationship of childhood abuse and household dysfunction to many of the leading causes of death in adults: The adverse childhood experiences (ACE) study. American Journal of Preventive Medicine, 14(4), 245-258. https://doi.org/10.1016/S0749-3797(98)00017-8

Ferguson, I. (2007). Increasing user choice or privatizing risk? The antinomies of personalization. British Journal of Social Work, 37(3), 387-403. Retrieved from https://doi.org/10.1093/bjsw/ bcm016.

Fledderus, J., Brandsen, T., \& Honingh, M. E. (2015). User co-production of public service delivery: An uncertainty approach. Public Policy and Administration, 30(2), 145-164. Retrieved from https://doi.org/10.1177/0952076715572362.

Flood, M. (2015). Work with men to end violence against women: A critical stocktake. Culture, Health \& Sexuality, 17(sup2), 159-176. Retrieved from https://doi.org/10.1080/13691058.2015.1070435.

Fulu, E., Miedema, S., Roselli, T., McCook, S., Chan, K. L., Haardörfer, R., . . Johnson, S. (2017). Pathways between childhood trauma, intimate partner violence, and harsh parenting: Findings from the UN multi-country study on men and violence in Asia and the Pacific The Lancet Globalization and Health, 5(5), e512-e522. Retrieved from https://doi.org/10.1016/S2214-109X(17)30103-1.

Gergen, K. J., \& Gergen, M. M. (2008). Social construction and research as action. In P. Reason \& H. Bradbury (Eds.), The Sage handbook of action research: Participative inquiry and practice (2nd ed., pp. 159-171). SAGE.

Gondolf, E. W. (2011). The weak evidence for batterer program alternatives. Aggression and Violent Behavior, 16(4), 347-353. Retrieved from https://doi.org/10.1016/j.avb.2011.04.011.

Haigh, R., \& Campling, P. (1999). Therapeutic communities : Past, present, and future. Jessica Kingsley Publishers.

Hasisi, B., Shoham, E., Weisburd, D., Haviv, N., \& Zelig, A. (2016). The "care package," prison domestic violence programs and recidivism: a quasi-experimental study. Journal of Experimental Criminology, 12(4), 563-586. https://doi.org/10.1007/ s11292-016-9266-y

Herring, S., Spangaro, J., Lauw, M., \& McNamara, L. (2013). The intersection of trauma, racism, and cultural competence in effective work with aboriginal people: Waiting for trust. Australian Social Work, 66(1), 104-117. https://doi.org/10.1080/0312407X. 2012.697566

Jenkins, A. (1990). Invitations to responsibility : The therapeutic engagement of men who are violent and abusive. Dulwich Centre Publications.

Jenkins, A. (2005) Shame, Realisation and Restitution: ethics of restorative practice, Australian and New Zealand Journal of Family Therapy, 27(3), pp. 153-156. Retrieved from https://doi.org/10. 1002/j.1467-8438.2006.tb00713.x

Jensen, P. R. (2018). Undignified dignity: Using humor to manage the stigma of mental illness and homelessness. Communication Quarterly, 66(1), 20-37. Retrieved from https://doi.org/10.1080/01463 373.2017.1325384.

Jewkes, R., Flood, M., \& Lang, J. (2015). From work with men and boys to changes of social norms and reduction of inequities in gender relations: A conceptual shift in prevention of violence against women and girls. The Lancet, 385(9977), 1580-1589. Retrieved from https://doi.org/10.1016/S0140-6736(14)61683-4.

Jury, R., \& Boxall K. (2018). Working with the enemy? Social work education and men who use intimate partner violence. Social Work Education, 37(4), 507-518. https://doi.org/10.1080/02615 479.2018.1433157

Jury, R., \& Boxall K. (2021). Exploring the involvement of men who use intimate partner violence in social work education: Student and service user views. International Social Work, 64(6), 917930. https://doi.org/10.1177/0020872819884988

Keenan, M. (2012). Researching the lives of Irish Roman Catholic clergy who have sexually abused minors: Collaborative inquiry. Qualitative Social Work, 11(3), 282-298. Retrieved from https:// doi.org/10.1177/1473325011400487.

Letherby, G. (2011). Feminist methodology. In M. Williams \& W. P. Vogt (Eds.), The SAGE handbook of innovation in social research methods (pp. 62-79). SAGE.

Machisa, M. T., Christofides, N., \& Jewkes, R. (2016). Structural pathways between child abuse, poor mental health outcomes and maleperpetrated intimate partner violence (IPV). PLoS One, 11(3), e0150986. https://doi.org/10.1371/journal.pone.0150986

Mayer, C., \& McKenzie, K. (2017). ' ...it shows that there's no limits': The psychological impact of co-production for experts by experience working in youth mental health. Health \& Social Care in the Community, 25(3), 1181-1189. Retrieved from https://doi.org/ 10.1111/hsc. 12418 .

McCarry, M., Larkins, C., Berry, V., Radford, L., \& Stanley, N. (2018). The potential for co-production in developing violence against women Services in Wales Social Policy and Society, 17(2), 193208. Retrieved from https://doi.org/10.1017/S1474746417000070.

Morris, J., Gibbs, C. A., Jonah, O. T., Bloomfield, S., Weatherstone, P. H., \& Ireland, J. L. (2019). Developing content to promote desistance in men who have committed intimate partner violence in same-sex relationships. European Journal of Probation, 11(2), 
96-113. Retrieved from https://doi.org/10.1177/2066220319 871454.

Moulding, N. (2018). 'Becoming a Better Man': narrating masculinities after childhood emotional abuse. Affilia - Journal of Women and Social Work, 33(1), 39-55. Retrieved from https://doi.org/10. $1177 / 0886109917729665$.

New, C. (2003). Feminism, critical realism and the linguistic turn. In J. Cruickshank (Ed.), Critical realism : The difference it makes (pp. 57-74). Taylor \& Francis Group.

O'Sullivan, T. A., \& Jefferson, C. G. (2020). A review of strategies for enhancing clarity and reader accessibility of qualitative research results. American Journal of Pharmaceutical Education, 84(1), 7124-7124. Retrieved from https://doi.org/10.5688/ajpe7124.

Pearce, S., \& Pickard, H. (2013). How therapeutic communities work: Specific factors related to positive outcome. International Journal of Social Psychiatry, 59(7), 636-645. Retrieved from https://doi. org/10.1177/0020764012450992.

Perel, G., \& Peled, E. (2008). The fathering of violent men: Constriction and yearning. Violence Against Women, 14(4), 457. Retrieved from https://doi.org/10.1177/1077801208314846.

Portnoy, G. A., \& Murphy, C. M. (2017). Using reoffenders' experiences and perspectives to improve intimate partner violence treatment. Journal of Interpersonal Violence. Retrieved from https:// doi.org/10.1177/0886260517714439

Remedios, J. D., \& Snyder, S. H. (2018). Intersectional oppression: Multiple stigmatized identities and perceptions of invisibility, discrimination, and stereotyping. Journal of Social Issues, 74(2), 265-281. Retrieved from https://doi.org/10.1111/josi.12268.

Richards, T. N., Tillyer, M. S., \& Wright, E. M. (2017). Intimate partner violence and the overlap of perpetration and victimization: Considering the influence of physical, sexual, and emotional abuse in childhood. Child Abuse \& Neglect, 67, 240-248. Retrieved from https://doi.org/10.1016/j.chiabu.2017.02.037.

Roberts, A. L., McLaughlin, K. A., Conron, K. J., \& Koenen, K. C. (2011). Adulthood stressors, history of childhood adversity, and risk of perpetration of intimate partner violence. American Journal of Preventive Medicine, 40(2), 128-138. Retrieved from https://doi.org/10.1016/j.amepre.2010.10.016.
Roguski, M., \& Gregory, N. (2014). Former family violence Perpetrators' narratives of change. Retrieved from https://ndhadeliver. natlib.govt.nz/delivery/DeliveryManagerServlet?dps_pid=IE255 96493\&dps_custom_att_1=ilsdb.

Sprang, G., Swan, S., \& Coker, A. L. (2020). Innovations in interpersonal violence prevention: Research, collaboration and opportunities. Journal of Family Violence. Retrieved from https://doi.org/ 10.1007/s10896-020-00159-z

State of Victoria. (2016). Royal Commission into Family Violence: Report and Recommendations. Retrieved from http://rcfv.archi ve.royalcommission.vic.gov.au/Report-Recommendations.html

Towns, A. J., \& Terry, G. (2014). "You're in that realm of unpredictability": Mateship, loyalty, and men challenging men who use domestic violence against women. Violence Against Women, 20(8), 1012-1036. Retrieved from https://doi.org/10.1177/10778 01214546232.

Voith, L. A., Logan-Greene, P., Strodthoff, T., \& Bender, A. E. (2020). A paradigm shift in batterer intervention programming: A need to address unresolved trauma. Trauma, Violence, \& Abuse, $O(0)$, Advance Online. Retrieved from https://doi.org/10.1177/15248 38018791268.

Westmarland, N., \& Kelly, L. (2012). Why extending measurements of 'success' in domestic violence perpetrator Programmes matters for social work. The British Journal of Social Work, 43(6), 1092-1110. Retrieved from https://doi.org/10.1093/bjsw/bcs049.

Wolcott, H. F. (1994). Transforming qualitative data : Description, analysis, and interpretation. Sage Publications.

World Health Organization. (2013). Global and regional estimates of violence against women: prevalence and health effects of intimate partner violence and non-partner sexual violence (9241564628): Retrieved from https://www.who.int/reproductivehealth/publicatio ns/violence/9789241564625/en/

Publisher's Note Springer Nature remains neutral with regard to jurisdictional claims in published maps and institutional affiliations. 